\title{
Body Condition Score and Body Weight Effects on Dystocia and Stillbirths and Consequent Effects on Postcalving Performance
}

\author{
D. P. Berry, ${ }^{\star 1}$ J. M. Lee, $†$ K. A. Macdonald, $†$ and J. R. Roche†‡ \\ ${ }^{*}$ Teagasc, Moorepark Dairy Production Research Centre, Fermoy, Co. Cork, Ireland \\ †Dexcel Ltd., Hamilton, New Zealand \\ fUniversity of Tasmania, PO Box 3523, Burnie, Tasmania 7320, Australia
}

\begin{abstract}
The objective of this study was to quantify the effect of periparturient body condition score (BCS) and body weight (BW) related traits on the incidence of calving dystocia and stillbirths, and to determine any consequent effect of dystocia and stillbirths on BCS, BW, milk production, udder health, and fertility in grazing Holstein-Friesian dairy cows. Up to 2,384 lactation records with data on calving dystocia or stillbirths were available from one research herd across $15 \mathrm{yr}$. Mixed models and generalized estimating equations were used to quantify all effects. Body condition score or BW $8 \mathrm{wk}$ precalving or at calving, or change precalving did not significantly affect the odds of a difficult calving or stillbirth. Cows that experienced dystocia lost, on average, more BCS and BW between calving and nadir and had significantly reduced nadir BCS and BW. Incidence of stillbirths did not affect BCS in early lactation, although BW loss postpartum was greater following a stillbirth. A dystocia or stillbirth event was associated with reduced $60-\mathrm{d}$ milk yield (42 and $52 \mathrm{~kg}$ less milk produced following a difficult calving or a stillbirth, respectively). The effect of stillbirth on milk yield was independent of dystocia. Cows that experienced dystocia had reduced milk concentration of fat, protein, and lactose, whereas average somatic cell score (natural logarithm of somatic cell count) in the first 60 -d postpartum was elevated. There was no significant effect of dystocia or stillbirth on clinical mastitis, but pregnancy rates to first service and throughout the 12 -wk breeding season were compromised in cows that had experienced difficulty at calving. The significance of the effects of stillbirth on somatic cell score and reduced fertility were mediated through its association with dystocia. In conclusion, periparturient BCS and $\mathrm{BW}$ within the range observed in the current study did not significantly affect
\end{abstract}

Received January 11, 2007.

Accepted May 1, 2007.

${ }^{1}$ Corresponding author: Donagh.berry@teagasc.ie incidence of dystocia and stillbirth, but these events negatively affected cow performance in early lactation. Key words: body condition score, body weight, dystocia and stillbirth, reproduction

\section{INTRODUCTION}

Calving dystocia may be broadly defined as a delivery requiring more assistance than desirable whereas stillbirth usually includes calf mortality shortly before, during, and shortly after parturition (Meijering, 1984). Calving dystocia and stillbirth, both of which are correlated (Meijering, 1984; Meyer et al., 2001; Steinbock et al., 2003), can be of considerable economic cost to dairy farmers (Meijering, 1984; Dematawewa and Berger, 1997; Meyer et al., 2001). Furthermore, incidence of dystocia and stillbirth (Meyer et al., 2001; Hansen et al., 2004; Heringstad et al., 2007) is reportedly increasing in some countries, thereby increasing the importance of identifying potential risk factors. Most countries operate a recording system for dystocia, which although differing in the detail of the score, usually involves farmer scoring on an ordinal scale that increases with the level of assistance required until reaching a maximum (usually caesarean section).

The incidence of dystocia and stillbirths tend to be population specific because of genetic factors (Manfredi et al., 1991; Steinbock et al., 2003) and a range of nongenetic factors (Meijering, 1984). Heritability estimates for direct calving difficulty range from $<0.01$ to 0.17 and from $<0.01$ to 0.12 for maternal calving difficulty (Manfredi et al., 1991; Steinbock et al., 2003); and direct and maternal heritability estimates for stillbirths in dairy cattle range from $<0.01$ to 0.12 and from $<0.01$ to 0.08 (Steinbock et al., 2003), respectively.

Nongenetic factors affecting the risk of dystocia and stillbirths were reviewed by Meijering (1984) and include year (Meyer et al., 2001; Johanson and Berger, 2003; Steinbock et al., 2003), time of year at calving (Meyer et al., 2001; Johanson and Berger, 2003; Steinbock et al., 2003), herd (Steinbock et al., 2003), dam parity (Thompson et al., 1983; Meyer et al., 2001; 
Johanson and Berger, 2003; Steinbock et al., 2003) and age at calving within parity (Ettema and Santos, 2004), sex of calf (Chassagne et al., 1999; Johanson and Berger, 2003; Ettema and Santos, 2004), calf birth weight (Johanson and Berger, 2003), gestation length (Meyer et al., 2001; Johanson and Berger, 2003), and whether the calf was a singleton or twin (Peeler et al., 1994; Ettema and Santos, 2004). Incompatibility between the size of the calf and pelvic opening of the dam has also been associated with dystocia (Johnson et al., 1988). Few studies, however, have investigated the effect of periparturient BCS (Gearhart et al., 1990; Waltner et al., 1993; Chassagne et al., 1999), BW (Erb et al., 1985), or body size (Thompson et al., 1983) on incidence of calving dystocia and stillbirth, and to our knowledge, the effects have never been quantified on cows fed at pasture. One potential reason for the lack of research on this topic is the paucity of data on BCS and BW in the periparturient period.

Several studies have implicated dystocia or stillbirth as contributing factors to reduced milk yield (Dematawewa and Berger, 1997; Rajala and Gröhn, 1998), impaired health (Erb et al., 1985; Peeler et al., 1994), inferior fertility (Thompson et al., 1983; Dematawewa and Berger, 1997), and reduced life span (Erb et al., 1985; Dematawewa and Berger, 1997) of the cow. Domecq et al. (1997) reported an average reduction of 273 $\mathrm{kg}$ of milk yield per cow in the first $120 \mathrm{~d}$ of lactation in multiparous cows that had experienced difficulty at calving compared with cows that had not. To our knowledge, however, no study has ever attempted to quantify the effect of dystocia or stillbirth on BCS and BW in the immediate postpartum period.

Therefore, the objectives of this study were to quantify the effect of periparturient BCS- and BW-related traits on calving dystocia and stillbirth events, and to quantify the consequent effects of these events on BCS, $\mathrm{BW}$, milk production, udder health, and fertility in grazing Holstein-Friesian dairy cows. Results could be useful in determining an optimum periparturient BCS to minimize the risk of dystocia or stillbirth, and the associated effects on health, production, and reproduction.

\section{MATERIALS AND METHODS}

\section{Data Available}

The data set used in the present study, as well as a description of the research farm from which all data were recorded, were described previously by Berry et al. (2007) and Roche et al. (2007a,b). In summary, data on cow identification number, year of birth, parity number, and associated calving dates were extracted from the Dexcel research database on 2,635 lactations from 897 cows. Of the 897 cows, 374 were Jersey and the remainder was Holstein-Friesian. All cows resided at No. 2 Dairy, Dexcel (Hamilton, New Zealand) between 1986 and 2000, inclusive. The period in question incorporated 64 research treatment farmlets undertaken during multiple lactations (141 different herd $\times$ year farmlets) that compared different pasture species and cultivars, different grazing rotation lengths, systems that optimized use of nitrogen fertilizer and supplementary feeds, research to determine the most profitable stocking rate for grazing dairy systems, and comparisons of the profitability of Holstein-Friesian and Jersey heifers under grazing systems.

Dystocia at calving was categorized as no assistance, minor assistance, or major assistance. Assistance was deemed to have occurred if there was a requirement for the calf to be pulled either by hand or with a winchtype device. The "major assistance" category was used when 2 people or veterinary intervention were required. The health of the calf was categorized as stillborn, weak, or healthy. Sex of the calf and incidence of twins, whether parturition was hormonally induced, and premature births were also recorded. Weight of each calf was recorded at birth. No calving information was available for 25 of the lactations in the data set. Sire of the calf was recorded for all but 42 of calves born.

Individual milk yield was recorded weekly and milk fat, $\mathrm{CP}$, and lactose concentration, and SCC of the milk were determined by Milkoscan (Foss Electric, Hillerød, Denmark) on the individual p.m. and a.m. aliquot samples collected. Body condition score and BW were assessed within 1 wk of calving, and every 2 wk during the intercalving period following the a.m. milking. Body condition score was assessed by palpating individual body parts and was recorded on a 10-point scale, for which $1=$ emaciated and $10=$ obese (Roche et al., 2004). Across the entire study period, only 4 trained personnel assessed BCS on all cows. Furthermore, all of these assessors were trained by the same individual. Body weight was measured using a calibrated electronic scale (Tru-Test, Auckland, New Zealand). In total, 95,971 milk test-day records, 68,986 BCS records, and 68,980 BW records were available for inclusion in the analysis. The mean number of milk yield records, BCS records, and BW records per lactation was 37,23 , and 23 , respectively.

Reproduction data were available on 2,594 lactations. The reproduction data included dates when standing estrus was expressed and observed by farm staff, service dates to $\mathrm{AI}$ or bull breeding events, and pregnancy diagnoses. Pregnancy diagnosis was performed by manual palpation of uterine contents at least $5 \mathrm{wk}$ after the end of the 12-wk mating period. These data are described in more detail by Roche et al. (2007b). 


\section{Data Editing}

The editing and generation of BCS, BW, milk production, health, and fertility variables were identical to those previously described (Berry et al., 2007; Roche et al., 2007a,b).

Body condition score and BW precalving were determined as the BCS or BW record nearest to $8 \mathrm{wk}$ precalving, but between 6 and $10 \mathrm{wk}$ precalving. When $2 \mathrm{BCS}$ or BW records were available equidistant from wk 8 , the earlier record precalving was retained. Additionally all BCS and BW records in the 9 wk before calving were retained to determine respective precalving change. A linear regression in PROC REG (SAS Institute, 2006) was fitted through these records for each cow separately and the linear coefficient determined; the linear regression was only fitted through lactations with at least 2 precalving records. The regression coefficient was recoded as 1,2 , or 3 if the regression coefficient was negative, zero, or positive, respectively.

The BCS and BW record considered to be that at calving was the first record postcalving but within $7 \mathrm{~d}$ of calving. Nadir BCS was the first postcalving record immediately followed by 2 greater consecutive values; nadir BW was determined using the same methodology. The days postcalving corresponding to nadir BCS or nadir BW were also retained.

Level of BCS or BW change from 8 wk precalving to calving and from calving to nadir was calculated as the earlier BCS or BW record minus the later record; hence, a positive value was indicative of a loss in BCS or BW, and vice versa. All variables were normally distributed with the exception of BCS and BW change to nadir and DIM to nadir. With the exception of the BCS change from calving to nadir, Box-Cox transformations revealed that the natural logarithm of these variables, following the addition of a constant to avoid zeros, was optimal. The shift constants used were 1 for DIM to BCS or BW nadir, and 70 for the amount of BW loss to nadir. The square root of BCS change from calving to nadir was used as the method of transformation.

The Wilmink exponential function (Wilmink, 1987) was fitted to milk test-day yields within lactation and is described as

$$
\text { Milk }_{t}=a+b e^{-0.05 t}+c t
$$

where Milk $_{t}$ represents milk yield $(\mathrm{kg})$ at day $t$ of lactation, and $a, b$, and $c$ are estimated parameters relating to the height of the curve, the initial phase of postcalving incline to peak, and the subsequent postpeak decline phase, respectively. The regression parameters were estimated for each cow-lactation separately using PROC NLIN (SAS Institute, 2006). The first derivative of the Wilmink function with respect to time (dMilk / $d t$ ) for each cow-lactation was set equal to zero and solved for DIM to determine DIM at peak yield; DIM was rounded to the nearest whole integer. Peak yield was the yield corresponding to DIM at peak. Total milk yield in the first $270 \mathrm{~d}$ was derived as the definite integral of the function for each lactation.

Preliminary analysis of the SCC data revealed a positively skewed distribution. A natural log transformation normalized the distribution; this variable will be herein referred to as SCS. Average SCS was defined as the mean of all test-day records in the first $60 \mathrm{~d}$ of lactation. A dichotomous variable, high SCC (HSCC), was defined as 1 if an individual SCC test-day record greater than 250,000 cells $/ \mathrm{mL}$ occurred within $60 \mathrm{~d}$ postcalving; if no test-day SCC greater than 250,000 cells $/ \mathrm{mL}$ existed, then HSCC was coded as 0 . Clinical mastitis (CM) was recorded by the herdsman on the observation of clots in the milk with or without signs of udder redness, soreness, or inflammation (International Dairy Federation, 1987). The annualized incidence proportion of $\mathrm{CM}$ was determined on an intercalving interval basis (i.e., $\mathrm{CM}=1$ if a case of $\mathrm{CM}$ was observed from $1 \mathrm{wk}$ precalving to $365 \mathrm{~d}$ postcalving, otherwise $\mathrm{CM}=0$ ) and separately within -7 to $60 \mathrm{~d}$ relative to calving. These definitions are the same as those reported by Berry et al. (2007).

Details of the derivation of the reproduction variables are given by Roche et al. (2007b). In summary, a binary variable (CYCLE) was defined as 1 if estrus was detected in a cow before the start of the breeding season. Premating estrus records $(n=928)$ were only available from 1996 to 2000 and included in the analysis of CYCLE. The 21-d submission rate (SR21) was constructed by coding cows with an insemination date within the first $21 \mathrm{~d}$ from planned start of mating (PSM) as 1, whereas those with no insemination date within the first $21 \mathrm{~d}$ were coded 0. Pregnant to first service (PFS) was coded as 1 if a cow received only one service and was diagnosed as pregnant at the end of the season. Pregnant within $21 \mathrm{~d}$ of the onset of breeding (P21) was coded as 1 if a lactation record, with at least one service, did not receive a service following $21 \mathrm{~d}$ of breeding, and was subsequently confirmed pregnant. A lactation record received a P21 record of 0 if a service was obtained sometime after $21 \mathrm{~d}$ of breeding, or if the cow was diagnosed as nonpregnant. Similar descriptors were used for pregnant within either $42 \mathrm{~d}(\mathbf{P 4 2})$ or 84 d (P84) after PSM.

Dystocia was dichotomized into no calving assistance $($ dystocia $=0)$ or minor plus major assistance $($ dystocia $=$ 1). Stillbirth was coded as 1 if a stillbirth occurred, otherwise 0 . Hormonally induced calvings $(n=253)$ and premature births $(n=5)$ were removed from all 
analyses. Stillbirth was included in all analyses as a binary variable.

Other Possible Explanatory Variables. Parity was recoded as $1,2,3,4$, and $5+$. Week of the year at calving was determined for all lactations. Because of small numbers, cows calving before wk 27 (i.e., early July) were grouped together as were cows calving later than wk 35 (i.e., early September). Year of calving was categorized as year. Parity, breed, week of year at calving, year of calving, and treatment farmlet operated on the research farm since 1986 were considered as class variables. These variables were first described by Roche et al. (2007a,b) and Berry et al. (2007) using the same data set to that used in the present study, when they related BCS and BW to milk production, fertility, and udder health, respectively.

\section{Statistical Analysis}

Factors Affecting Dystocia or Stillbirth. Factors affecting dystocia and stillbirths were analyzed separately using generalized estimating equations (GEE) in PROC GENMOD (SAS Institute, 2006) with a logit link function and an assumed binomial error distribution. Sire of the calf was included as a repeated effect with a compound symmetry correlation structure assumed among progeny within sire; calving records for which the sire of the calf was not identified $(n=42)$ were omitted. A multiple regression model was built using forward $(P<0.15)$ and backward $(P>0.05)$ steps in which the confounding factors tested for inclusion in the model were farmlet, year, week of calving, breed of dam, parity of dam, sex of calf, history of calving difficulty in the immediately previous calving, and incidence of twins as well as biologically plausible interactions. Calving dystocia was also tested as a potential confounding factor in the analysis of stillbirths whereas the effect on dystocia of the ratio of the birth weight of the calf relative to the calving $\mathrm{BW}$ of the dam was also investigated. The presence of multicollinearity was avoided by monitoring the model solutions and standard errors at each step. Following the development of the multiple regression model with confounding factors, BCS and BW precalving and at calving as well as change in BCS and BW precalving were individually included in the model. Significance was based on the GEE score statistic and was declared at $P<0.05$. A total of 2,342 records were available for inclusion in this analysis.

Odds ratios were calculated as the exponent of the model solutions. An odds ratio compares opposing probabilities to determine the more likely result for a given outcome (e.g., the probability of dystocia or a stillbirth). In the present study, if the odds ratio is 1.5 , then cows exhibiting the level of the independent variable under investigation have a $50 \%$ greater likelihood of a positive outcome (i.e., dystocia). An odds ratio of 2 reflects double the likelihood of the outcome under investigation.

Effect of Dystocia and Stillbirths on Subsequent Performance. The effect of dystocia and stillbirths on 60-d and 270-d milk yield, SCS, fat, protein, and lactose concentration as well as parameters describing the milk lactation profile was determined using multiple regression mixed models (SAS Institute, 2006) through the inclusion of either dystocia or stillbirths as a main effect or in a 2-way interaction with parity or breed if significant $(P<0.05)$. The effect of dystocia or stillbirths on the logit of an HSCC, CM, CYCLE, PFS, P21, P42, or P84 was determined using GEE in PROC GENMOD (SAS Institute, 2006).

Twin births were removed from these analyses to avoid complications associated with quasi-complete separation of the data. Confounding factors included in the model were those previously reported by Berry et al. (2007) and Roche et al. (2007a,b) for udder health, milk production, and fertility, respectively. Up to 2,327 lactation records were available for inclusion in these analyses.

\section{RESULTS}

The incidence of dystocia in the present data set was $7 \%$, and the incidence of stillbirth and twins was 6 and $2 \%$, respectively. Mean values for BCS, BW, milk production, and SCS are summarized in Table 1. Mean CYCLE, SR21, PRF, PR21, PR42, and PR48 were 0.75, $0.95,0.59,0.57,0.76$, and 0.93 , respectively. Mean incidence of CM in early lactation was 0.10 , whereas across the entire lactation the mean incidence was 0.19 . Factors affecting the incidence of dystocia were parity of dam, sex of calf, whether the calf was a singleton or twin, and a linear regression on the weight of the calf. Neither BCS nor BW precalving or at calving or change precalving significantly affected the likelihood of dystocia in the multiple regression model. Furthermore, no significant interactions were evident. Without calf birth weight included in the model, breed significantly $(P<0.05)$ affected the likelihood of a difficult calving with 7.3 times greater (95\% confidence interval: 3.61 to 14.61) odds in a Friesian compared with a Jersey dam. Excluding twin births, birth weight of male calves $(37 \mathrm{~kg})$ was significantly $(P<0.001)$ greater than birth weight of female calves $(34 \mathrm{~kg})$.

First-parity cows were more likely to have a difficult calving relative to older cows, whereas older parity cows did not significantly differ from each other in risk of dystocia. The odds (95\% confidence intervals in parenthesis) of dystocia for a second, third, fourth, and fifth 
Table 1. Summary statistics for the BCS, BW, milk production, and SCS traits analyzed

\begin{tabular}{|c|c|c|c|}
\hline Trait & $\mathrm{n}$ & Mean & SD \\
\hline Precalving BCS, units & 1,265 & 4.6 & 0.61 \\
\hline Calving BCS, units & 2,338 & 4.7 & 0.61 \\
\hline Nadir BCS, units & 2,298 & 3.8 & 0.60 \\
\hline Precalving BCS change (units $/ \mathrm{d} \times 100$ ) & 1,419 & 0.41 & 1.280 \\
\hline BCS loss to nadir, ${ }^{1}$ units & 2,294 & $0.84(0.71)$ & 0.422 \\
\hline DIM to nadir BCS, ${ }^{1} \mathrm{~d}$ & 2,298 & $3.9(48)$ & 0.93 \\
\hline Precalving BW, kg & 1,265 & 476 & 67.8 \\
\hline Calving BW, kg & 2,337 & 441 & 74.3 \\
\hline Nadir BW, kg & 2,335 & 386 & 64.7 \\
\hline Precalving BW change, $\mathrm{kg} / \mathrm{d}$ & 1,419 & 0.49 & 0.628 \\
\hline BW loss to nadir, ${ }^{1} \mathrm{~kg}$ & 2,329 & $4.8(51.5)$ & 0.26 \\
\hline DIM to nadir BW, ${ }^{1} \mathrm{~d}$ & 2,335 & $3.4(29)$ & 0.62 \\
\hline 60-d milk yield, kg & 2,216 & 1,201 & 289.0 \\
\hline 270-d milk yield, kg & 2,216 & 4,255 & 870.6 \\
\hline Peak milk yield, kg & 2,216 & 21.2 & 4.83 \\
\hline DIM to peak milk yield, $d$ & 2,214 & 32.7 & 14.26 \\
\hline $60-\mathrm{d}$ fat percentage, $\%$ & 2,216 & 4.6 & 0.60 \\
\hline 270-d fat percentage, $\%$ & 2,216 & 4.9 & 0.70 \\
\hline 60-d protein percentage, $\%$ & 2,216 & 3.5 & 0.27 \\
\hline 270 -d protein percentage, $\%$ & 2,216 & 3.6 & 0.29 \\
\hline 60-d lactose percentage, $\%$ & 2,216 & 4.9 & 0.24 \\
\hline 270 -d lactose percentage, $\%$ & 2,216 & 4.8 & 0.20 \\
\hline Lactation SCS, units & 2,338 & 11.4 & 0.86 \\
\hline 60-d SCS, units & 2,239 & 11.2 & 1.05 \\
\hline
\end{tabular}

\footnotetext{
${ }^{1}$ Means and standard deviations are presented on a transformed scale but back-transformed means are presented in parentheses.
}

or greater parity cow relative to a first-parity heifer was 0.11 (0.06 to 0.22$), 0.12$ (0.06 to 0.22$), 0.09$ (0.04 to 0.22 ), and 0.12 (0.08 to 0.20 ), respectively. Calf birth weight was positively associated with the odds of dystocia. The probability of a difficult calving in a thirdparity cow giving birth to a male singleton calf of 20 , 30,40 or $50 \mathrm{~kg}$ birth weight was $1,2,5$, and $15 \%$, respectively; the mean calf weight of singletons in the data set was $35.7 \mathrm{~kg}$. In addition, a cow was 1.4 [95\% confidence interval (CI): 1.02 to 1.98] times more likely to have difficulty at calving when giving birth to a male calf, even following adjustment for difference in calf birth weight, whereas the odds of a difficult twin calving was 11.0-fold (95\% CI: 3.30 to 34.18 ) greater than that of a singleton. Furthermore, a larger calf birth weight relative to the $\mathrm{BW}$ of the dam at calving increased the likelihood of a difficult calving. For a cow calving for the first time the probability of difficult calving when the calf was a singleton male weighing $7.5 \%$ of the dam's BW at calving was $12.5 \%$, which increased to $26.5 \%$ when the calf weighed $10 \%$ of dam BW at calving.

Factors that significantly affected the likelihood of a stillbirth were parity of the dam, whether the calf was a singleton or twin, and whether assistance was provided at calving or not. Precalving, calving, or change in BCS and BW did not significantly affect the likelihood of a stillborn calf. There was an 8 times greater likelihood of a stillbirth (odds ratio $=8.3 ; 95 \%$ CI: 5.07 to 13.70) when assistance at calving was required. Furthermore, the odds of at least one stillbirth was 11.9 times greater (95\% CI: 5.72 to 24.67) in twins than for a singleton. The odds (95\% CI in parentheses) of stillbirth in second, third, fourth, and fifth or greater parity cows was 0.48 (0.24 to 0.96$), 0.43$ (0.21 to 0.89 ), 0.44 (0.26 to 0.75 ), and 0.56 (0.35 to 0.89 ), respectively.

\section{Effect of Dystocia on Subsequent Performance}

The effect of dystocia on BCS, BW, milk production, and SCS are summarized in Table 2. Cows that experienced dystocia lost more BCS and BW from calving to nadir and had reduced BCS and BW at nadir despite there being no significant effect on DIM at nadir. Total $60-$ and $270-\mathrm{d}$ milk yield was 42.0 and $61.9 \mathrm{~kg}$ less, respectively, in cows that experienced dystocia at calving compared with those that did not. Concentrations of milk fat, protein, and lactose were also significantly reduced in cows that had a difficult calving. Although there was no significant effect of dystocia on lactationaverage SCS, greater mean SCS in the first 60-d of lactation was observed in cows that had a difficult calving. Adjustment for differences in milk production simultaneous with other confounding factors in the model did not alter the level of significance for the effect of calving dystocia across any of the variables investigated and did not alter the sign of the solutions.

The effect of dystocia on the shape of the milk lactation curve differed significantly $(P<0.05)$ across parit- 
Table 2. Solutions (standard errors in parentheses) from the multiple regression analyses pertaining to the effect of dystocia and whether a calf was stillborn on BCS, BW, milk production, and SCS

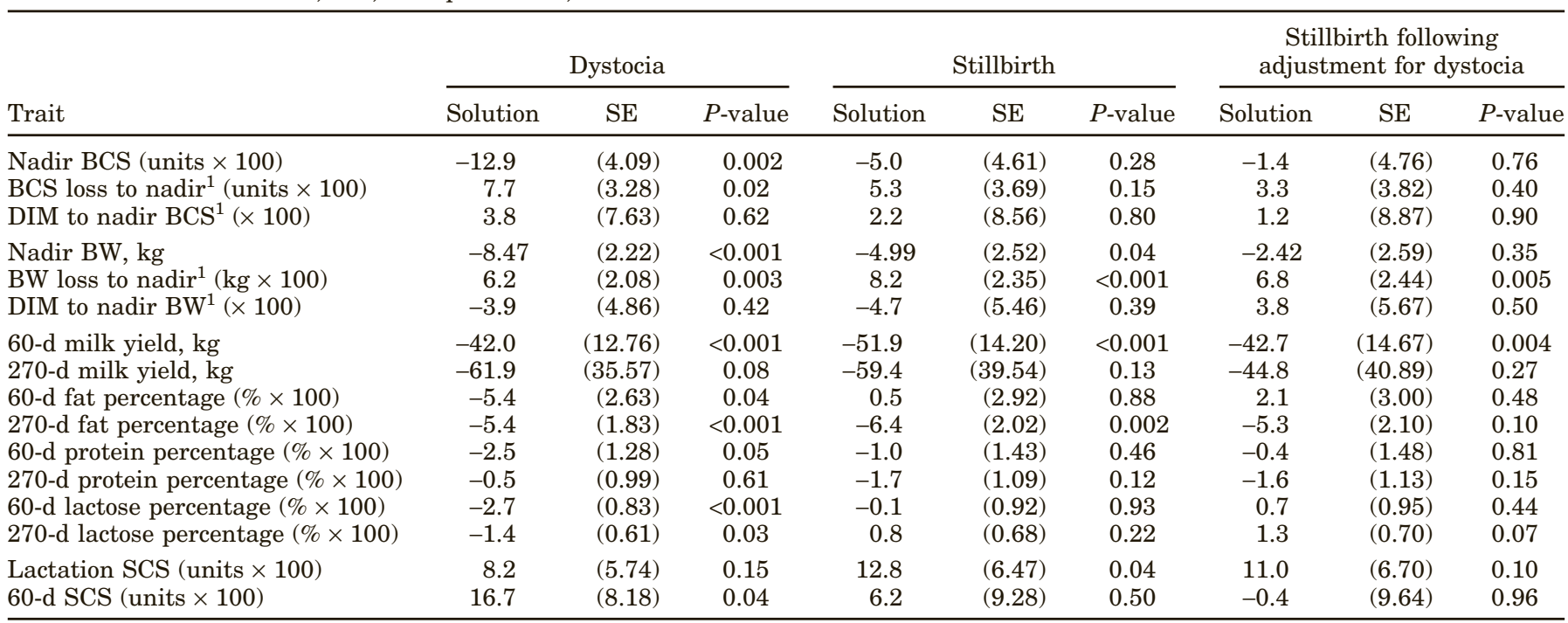

${ }^{1}$ Solutions presented are on a transformed scale.

ies (Table 3). Dystocia significantly decreased the height of the lactation profile in first-parity cows, whereas the effect was not significantly different from zero in older cows. The rate of increase in milk yield postcalving was smaller, albeit not significantly different from zero, in first-lactation cows that experienced a difficult calving although the persistency of the lactation was greater in these cows. Nonetheless, no significant interaction between dystocia and parity existed for peak milk yield and DIM to peak. Peak milk yield was $0.6 \mathrm{~kg}(\mathrm{SE}=0.21)$ smaller in cows that experienced dystocia, whereas the corresponding DIM to peak milk yield was $1.9 \mathrm{~d}$ longer $(\mathrm{SE}=1.1$ ).

Dystocia did not affect the likelihood of an HSCC or $\mathrm{CM}$ event in early lactation or during the lactation as a whole (Table 4). Although dystocia did not significantly affect submission rates, the odds of a cow becoming pregnant during the early to mid breeding season were reduced for cows that experienced dystocia at calving (Table 4).

\section{Effect of Stillbirth on Subsequent Performance}

Although the effect of a stillborn calf on dam BCS at nadir or BCS loss to nadir was not significant (Table 2), cows with a stillborn calf were lighter at nadir and lost more BW between calving and nadir. After adjusting for whether the stillborn calf was associated with a difficult calving, the effect of stillbirth on BW at nadir was not significant although the effect of stillbirth on BW loss to nadir remained significant and similar in magnitude (Table 2). Furthermore, the effect of stillbirth on BW loss did not differ significantly with incidence of dystocia.

Cows that had a stillborn calf yielded $51.9 \mathrm{~kg}$ less milk, on average, in the first $60 \mathrm{~d}$ of lactation, and milk

Table 3. Effect of dystocia (standard errors in parentheses) on parameters of the Wilmink function for different parities

\begin{tabular}{lccccc}
\hline & \multicolumn{5}{c}{ Parity } \\
\cline { 2 - 6 } Parameter $^{1}$ & 1 & 2 & 3 & 4 & $5+$ \\
\hline$a$ & -1.1 & 1.0 & 1.5 & -1.6 & -0.6 \\
& $(0.36)$ & $(0.84)$ & $(0.77)$ & $(0.88)$ & $(0.60)$ \\
$b(\times 100)$ & 15.4 & -197.3 & -287.9 & 47.1 & -168.9 \\
& $(51.55)$ & $(127.42)$ & $(118.29)$ & $(133.67)$ & $(90.30)$ \\
& 4.8 & -4.9 & -8.8 & 12.6 & 1.7 \\
& $(1.72)$ & $(4.22)$ & $(3.91)$ & $(4.42)$ & $(2.99)$ \\
\hline
\end{tabular}

\footnotetext{
${ }^{1} a, b$, and $c$ are estimated parameters of an exponential function $\left(M i l k_{t}=a+b e^{-0.05 t}+c t\right)$ relating to the height of the curve, the initial phase of postcalving incline to peak, and the subsequent postpeak decline phase, respectively.
} 
Table 4. Effect of dystocia and stillbirth on the odds ratios [OR; 95\% confidence intervals (CI) include in parentheses] of high SCC, clinical mastitis (CM), cycling at the start of the breeding season (CYCLE), submission rate (SR21) and pregnancy rate to first service (PRF) or in the first 21 (PR21), 42 (PR42), or 84 (PR84) days of the breeding season estimated from the multiple regression analyses

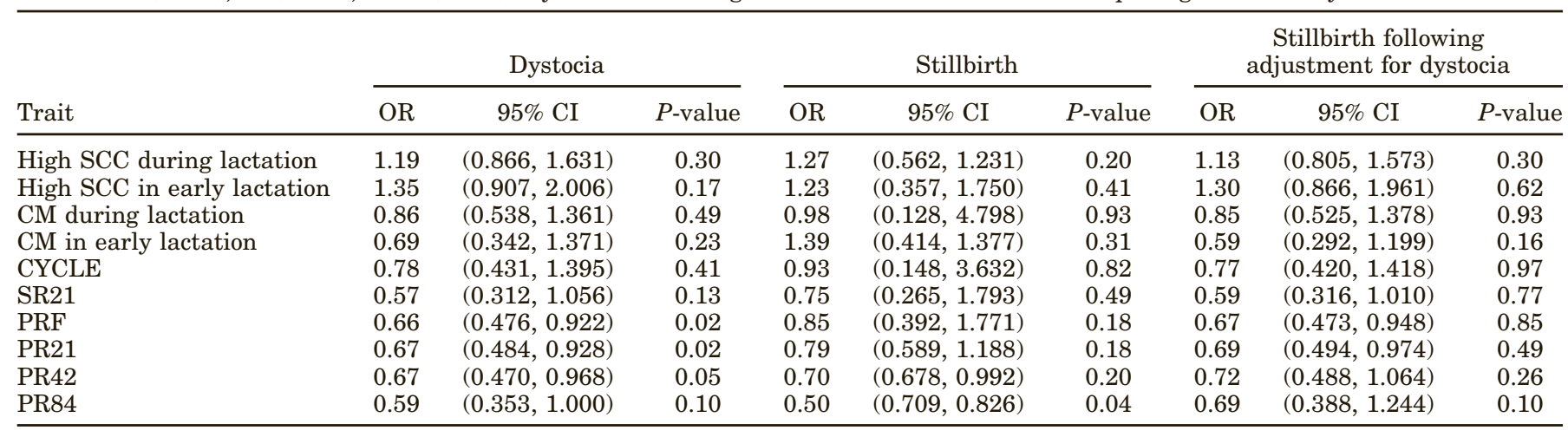

yield remained significantly lower even after adjustment for calving difficulty (Table 2). Furthermore, there was a significant effect of stillbirth on the height and persistency of the milk lactation profile (before and after accounting for calving dystocia). The height of the lactation profile was reduced $(-0.86 ; \mathrm{SE}=0.291)$, whereas the persistency was greater $\left(4.3 \times 10^{-3}\right.$; $\mathrm{SE}=1.4 \times 10^{-}$ $\left.{ }^{3}\right)$ in cows that had a stillborn calf. Least squares means for the $a, b$, and $c$ parameters of the Wilmink function for cows that had not had a stillbirth were 23.1, -6.23 , and -0.064 , respectively. The effect of a stillborn calf on peak milk yield and DIM to peak milk yield differed significantly with parity. Peak milk yield associated with the birth of a stillborn calf was lower in every parity ( -2.0 to $-0.4 \mathrm{~kg}$ ) except third-parity cows $(+0.6$ $\mathrm{kg} ; \mathrm{SE}=0.71)$, with the negative effect being greater in older cows. Similarly, DIM to peak milk yield was longer in all parities (1.9 to $8.7 \mathrm{~d}$ ) except third-parity cows $(-7.9 \mathrm{~d}$; $\mathrm{SE}=3.67)$, with the effect being greater in older cows. The significance of these effects remained even after adjusting for dystocia in the multiple regression model.

A stillbirth was associated with significantly greater average lactation SCS, and, although the trend was consistent for early lactation SCS, the latter was not significantly different from zero (Table 2). Nonetheless, neither effect was significantly different from zero when calving dystocia was included in the multiple regression model. Stillbirth did not affect the odds of an occurrence of CM (Table 3). The negative effect of stillbirth on the likelihood of a successful pregnancy was significant for P84, although this effect was not significant when calving dystocia was also accounted for in the model (Table 3).

\section{DISCUSSION}

Some studies (Erb et al., 1985; Gearhart et al., 1990; Chassagne et al., 1999) have investigated the effect of periparturient BCS or BW on the incidence of calving dystocia or stillbirth in dairy cows, but the authors are unaware of any study on dairy cattle that has attempted to quantify the effect of calving dystocia or stillbirths on postpartum BCS and BW changes. This is mainly because of insufficient data on BCS and BW. The data set used in the present study, in which regular BW and BCS (scored by a small number of trained and calibrated classifiers) measurements were available across $15 \mathrm{yr}$, provide an excellent and unique opportunity to explore the effect of BW and BCS on calving performance traits and the subsequent impact of dystocia and stillbirth on BCS and BW change postpartum.

This study failed to identify any significant association between periparturient BCS or BW and calving performance, although dystocia and stillbirth were associated with greater BCS and BW losses in early lactation, reduced milk yield, and impaired health and fertility. The incidence of dystocia observed in the present study is comparable to other international estimates in primiparous and multiparous cows (Fourichon et al., 2001; Steinbock et al., 2003). Incidence of stillbirths in the present study (6\%) was also within the range reported by others for a similarly defined trait (Fourichon et al., 2001; Johanson and Berger, 2003; Steinbock et al., 2003; Hansen et al., 2004). The twinning rate in the present study (2\%), although smaller than reported in some studies (Peeler et al., 1994), was within the range reported by others (Eddy et al., 1991).

\section{Effect of Periparturient BCS and BW on Dystocia and Stillbirth}

Consistent with previous reports, there was a greater likelihood of dystocia (Peeler et al., 1994; Dematawewa and Berger, 1997; Steinbock et al., 2003) and stillbirths or perinatal mortality (Peeler et al., 1994; Meyer et al., 2001; Johanson and Berger, 2003) in first-parity dairy cows. Similarly, the greater likelihood of a difficult calv- 
ing or stillbirth in male calves is in agreement with previous findings (Chassagne et al., 1999; Johanson and Berger, 2003; Ettema and Santos, 2004). Less research is available on the effect of twin births on dystocia and stillbirth because most research studies remove twin births in their editing processes (Johanson and Berger, 2003; Steinbock et al., 2003). Nevertheless, the greater observed incidence of dystocia and stillbirth in twin calving in the present study is in agreement with previous results (Echternkamp and Gregory, 1999; Ettema and Santos, 2004). The greater incidence of dystocia in twin births could be expected given the greater likelihood of malpresentation (Echternkamp and Gregory, 1999). No data on malpresentation, however, was available in the present study. The greater likelihood of a stillborn calf following dystocia also corroborates other studies (Peeler et al., 1994; Chassagne et al., 1999; Meyer et al., 2001). Meijering (1984) stated that calves requiring assistance at parturition might incur severe acidosis because of oxygen deprivation, with subsequent effects on the function of vital organs and overall vitality.

Meijering (1984), following a review of the literature, concluded that the effect of calf birth weight on dystocia was nonlinear. In the present study, however, a nonlinear effect of calf birth weight on dystocia was not significant but the likelihood of dystocia increased linearly with calf weight, which is consistent with results from a recent study at a research farm in the United States (Johanson and Berger, 2003). Despite the inclusion of calf weight in the multiple regression model, sex of the calf still had a significant effect on the likelihood of dystocia, again in agreement with the report of Johanson and Berger (2003). This indicates, therefore, that differences between calf sex other than birth weight (most likely morphological) influence dystocia. Incompatibility between the size of the calf and pelvic opening of the dam has also been reported to be associated with dystocia (Johnson et al., 1988). Although no data were available in the present study on dam pelvic opening, the risk of dystocia increased as the ratio of calf birth weight to cow BW at calving increased. Contrary to the report of Johanson and Berger (2003), calf birth weight was not a risk factor for stillbirth.

Consistent with the results presented here, Gearhart et al. (1990) did not identify any significant relationship between BCS at calving and dystocia in multiparous Holstein-Friesian dairy cows. They also reported no significant effect of BCS at calving on the incidence of retained placenta, metritis, or other metabolic or reproductive diseases (Gearhart et al., 1990). In contrast to the present study, however, Gearhart et al. (1990) reported that cows losing body condition during the dry period were at greater risk of dystocia in the following calving, with a 1-unit increase in BCS loss manifesting itself as 1.85 times greater odds of dystocia. Gearhart et al. (1990) indicated that one potential cause of the significant association between BCS change precalving and dystocia may be because of the herd manager attempting to achieve target BCS at calving, thereby necessitating a reduction in BCS in cows overconditioned at drying off. In the study of Gearhart et al. (1990), 8\% of the cows were classified as being overconditioned at dry off, whereas in the present study, $0.32 \%$ ( $n=4)$ of cows were overconditioned when using the same BCS threshold converted to the 10-point scale (Roche et al., 2004). Change in BCS precalving seems to be the mediating factor contributing to dystocia because the significance of BCS at dry off on dystocia in a univariate analysis was no longer significant in a multiple regression model when precalving BCS change was included in the model (Gearhart et al., 1990). Hence, the lack of a significant effect of either BCS at 8 wk precalving or BCS change precalving on dystocia or stillbirths in the present study is likely a result of very few overconditioned cows. A similar conclusion was presented by Waltner et al. (1993), who failed to identify any significant relationship between either BCS at dry off or calving on dystocia in primiparous or multiparous cows because only a small proportion of cows in that study were either very thin or very fat at these periods. Furthermore, Ruegg and Milton (1995) did not identify any significant association between BCS at calving and dystocia although the number of overconditioned cows was again small in that study. The lack of effect of precalving BCS and BCS change on the odds of stillbirth in the current study compared with the greater odds of a stillborn calf in cows calving with a BCS of greater than 4 (BCS scale: 1 to 5 ) in the work of Chassagne et al. (1999) further support the involvement of obesity in these disorders.

Thompson et al. (1983) reported a significant reduction in dystocia as dam size increased in first- and second-parity dairy cows, although the effect in third-parity and older cows was not significant. Phenotypic correlations between body size measures and BW are strong (Berry et al., 2004), indicating that lighter cows in first and second parity were predisposed to a greater risk of dystocia. Erb et al. (1985) also reported a significant reduction in dystocia as weight at calving in heifers increased, although BW at calving was not a significant predictor of dystocia in multiparous cows. One disadvantage, however, of most studies is the failure to account for assortative mating because of (most likely) a lack of data. Farmers may consciously mate genetically easier-calving sires to smaller cows thereby masking the effect of dam BW on dystocia. 


\section{Effect of Dystocia and Stillbirths on BCS and BW Postpartum}

Little is known of the effect of dystocia or stillbirth on postpartum BCS and BW in dairy cows. Drennan and Berry (2006) reported a greater loss of BCS in early lactation in beef cows that experienced a difficult calving than in those that calved unassisted. Despite a reduced 60-d milk yield in cows that experienced dystocia in the present study, and the associations between greater milk yield and reduced nadir BCS and BW, or greater BCS and BW loss to nadir (Roche et al., 2007a), cows that experienced dystocia lost more BCS and BW to nadir, resulting in reduced $\mathrm{BCS}$ and $\mathrm{BW}$ at nadir. Heuwieser et al. (1987) reported greater plasma cortisol concentrations in cows that experienced dystocia than in cows that did not. Nakao and Grunert (1990) speculated that a rise in plasma glucocorticoids or hyperactivity of the adrenal cortex might affect metabolic function and the immunocompetency of the cow, potentially resulting in increased susceptibility to disease. Such an immune response may also lead to a reduced abundance of hepatic growth hormone receptor-1A [M. Lucy (Univ. Missouri, Columbia) and J. R. Roche, unpublished data], increasing growth hormone concentration and lipolysis.

Stress induced by dystocia may also affect appetite (Ingvartsen et al., 2003) predisposing the cow to greater negative energy balance and thus requiring body tissue mobilization. Energy requirements may also be increased through invading pathogens eliciting a thermogenic response, the effect of which may be exacerbated by a depression in energy intake because of the released cytokines (Ingvartsen et al., 2003).

\section{Effect of Dystocia and Stillbirths on Milk Production, Health, and Fertility}

The lack of a significant effect of dystocia on 270-d milk yield despite its significant effect on $60-d$ milk yield indicated that the additional milk lost after $d 60$ was small and biologically unimportant. This is consistent with the results reported by Thompson et al. (1983), in that dystocia significantly reduced milk yield in early lactation but did not affect 305-d milk yield. This lack of effect of dystocia on the amount of milk produced postpeak, at least in the present study, is attributable to differences in the lactation profiles of cows that did or did not experience dystocia (Table 3). Lactation persistency was greater in primiparous cows that experienced dystocia, thereby negating the negative effect of dystocia on milk yield in early lactation. Such a "compensatory effect" may be because of a genetically predetermined milk lactation profile to which a cow will strive to attain, similar to the compensatory growth effect in growing beef cattle (Sainz et al., 1995). This is substantiated by significant genetic variation in the shape of milk lactation profiles previous reported in dairy cows by Berry et al. (2003) and is further substantiated by the delayed interval to peak milk yield in cows following a difficult calving, indicating that cows try to reach their genetic potential although their attempt may be delayed.

Although there is consensus that the effect of dystocia is modified by parity, there is inconsistency in the reports on this dystocia $\times$ parity interaction. Dematawewa and Berger (1997) reported a significant reduction in 305-d milk, fat, and protein yield following a difficult calving in primiparous cows, with the negative impact increasing as the level of difficulty increased. In second- and greater-parity cows, significant reductions in 305-d yield were only observed in cows experiencing serious calving difficulty (Dematawewa and Berger, 1997). Rajala and Gröhn (1998) reported no significant effect of dystocia on early lactation test-day milk yield in primiparous cows, although a significant reduction in milk yield in the first 2 wk postpartum was evident in second-parity cows that experienced dystocia. Furthermore, Domecq et al. (1997) reported no significant effect of dystocia on 120-d milk yield in primiparous cows although dystocia resulted in a significant reduction in 120-d milk yield in multiparous cows. Although, the effect of dystocia on 60-d and 270-d milk yield in the present study was not parity dependent, the effect on the lactation profile differed between parities.

The reduction in 60-d milk yield in the present study in cows that presented a stillborn calf, although smaller, is consistent with the effect of stillbirth on milk production reported by Chassagne et al. (1999). They reported a significantly reduced 305-d milk yield in cows that had a stillborn calf $(5,582 \mathrm{~kg})$ compared with cows that did not $(6,140 \mathrm{~kg})$. Additionally, Deluyker et al. (1991) reported a significant reduction in average milk yield in the first 5-d of lactation and cumulative milk yield in the first 21-d of lactation following the birth of a stillborn calf; no significant effect of stillbirth on milk yield later in lactation was observed in that study. This lack of effect in later lactation is consistent with the biologically small $(7.5 \mathrm{~kg})$ effect of dystocia on milk production after $60 \mathrm{~d}$ in the present study (Table 2). Furthermore, the significant effect of a stillborn calf on 60-d milk yield in the present study was independent of dystocia implying that factors other than a difficult calving caused a reduction in milk yield when the calf is stillborn. Chassagne et al. (1999) reported a greater incidence of retained fetal membranes following stillbirths, which may be one such contributing factor to the reduced milk production (Rowlands and Lucey, 1986). Chassagne et al. (1999) failed to identify a significant 
association between stillbirth and milk composition, although in the present study 270-d average milk fat concentration was lesser in lactations following the birth of a stillborn calf.

Although dystocia had no significant effect on the incidence of clinical mastitis in the ensuing lactation, it was associated with greater SCS in early lactation. Peeler et al. (1994) cited dystocia as a risk factor for clinical mastitis postpartum and before mating, indicating that the trauma associated with a difficult calving may have a debilitating effect, thereby increasing the cow's susceptibility to disease. Gearhart et al. (1990) and Erb et al. (1985) also reported a greater risk of metritis in cows following dystocia. Increased susceptibility to diseases, such as mastitis and metritis, may also be one method by which dystocia negatively affects reproductive performance (Erb et al., 1985). Such impaired fertility following dystocia has been previously reported (Dematawewa and Berger, 1997).

Consistent with the effect of dystocia on fertility, Chassagne et al. (1999) reported a reduced pregnancy rate to first service in cows that had a stillborn calf. The similar effect of stillbirth on reproductive performance (and SCS) in the present study seemed to be mediated through the effect of dystocia because the impact of stillbirth on SCS and reproductive performance was no longer significant following the inclusion of dystocia in the multiple regression model. Chassagne et al. (1999) did not adjust for dystocia in a multiple regression model when evaluating the effect of stillbirth on reproductive performance.

\section{CONCLUSIONS}

Periparturient BCS or BW did not significantly influence the risk of dystocia or stillbirth in the present study. This may be partly attributed to the lack of considerable variation in BCS either precalving or at calving or to assortative mating of easy-calving sires on smaller cows. Nonetheless, the frequency of cows considered overconditioned is generally low in most field studies (Gearhart et al., 1990; Ruegg and Milton, 1995) indicating that, within the ranges of periparturient BCS observed on most farms, BCS does not impact dystocia or stillbirth. In agreement with previous studies, dystocia, and to a lesser extent stillbirth, reduced milk production, increased SCS, and reduced reproductive performance.

\section{ACKNOWLEDGMENT}

The authors gratefully acknowledge J. Lancaster and C. Leydon-Davis for helping in the collection and collation of the data. This work was part-funded by New
Zealand dairy farmers, through the Dairy InSight research fund.

\section{REFERENCES}

Berry, D. P., F. Buckley, P. Dillon, R. D. Evans, and R. F. Veerkamp. 2003. Genetic parameters for body condition score, body weight, milk yield, and fertility estimated using random regression models. J. Dairy Sci. 86:3704-3717.

Berry, D. P., F. Buckley, P. Dillon, R. D. Evans, and R. F. Veerkamp. 2004. Genetic relationships among linear type traits, milk yield, body weight, fertility and somatic cell count in primiparous dairy cows. Irish J. Agric. Food Res. 43:161-176.

Berry, D. P., J. M. Lee, K. A. Macdonald, K. Stafford, L. Matthews, and J. R. Roche. 2007. Associations between body condition score, bodyweight and somatic cell count and clinical mastitis in seasonally calving dairy cattle. J. Dairy Sci. 90:637-648.

Chassagne, M., J. Barnouin, and J. P. Chaconac. 1999. Risk factors for stillbirth in Holstein heifers under field conditions in France: A prospective study. Theriogenology 51:1477-1488.

Deluyker, H. A., J. M. Gay, L. D. Weaver, and A. S. Azari. 1991. Change of milk yield with clinical disease for a high producing dairy herd. J. Dairy Sci. 74:436-445.

Dematawewa, C. M. B., and P. J. Berger. 1997. Effect of dystocia on yield, fertility, and cow losses and an economic evaluation of dystocia scores for Holsteins. J. Dairy Sci. 80:754-761.

Domecq, J. J., A. L. Skidmore, J. W. Lloyd, and J. B. Kaneene. 1997. Relationship between body condition scores and milk yield in a large dairy herd of high yielding Holstein cows. J. Dairy Sci. 80:101-112.

Drennan, M. J., and D. P. Berry. 2006. Factors affecting body condition score, live weight and reproductive performance in springcalving suckler cows. Irish J. Agric. Food Res. 45:25-38.

Echternkamp, S. E., and K. E. Gregory. 1999. Effects of twinning on gestation length, retained placenta, and dystocia. J. Anim. Sci. 77:39-47.

Eddy, R. G., O. Davies, and C. David. 1991. An economic assessment of twin births in British dairy herds. Vet. Rec. 129:526-529.

Erb, H. N., R. D. Smith, P. A. Oltenacu, C. L. Guard, R. B. Hillman, P. A. Powers, M. C. Smith, and M. E. White. 1985. Path model of reproductive disorders and performance, milk fever, mastitis, milk yield and culling in Holstein cows. J. Dairy Sci. 68:33373349 .

Ettema, J. F., and J. E. P. Santos. 2004. Impact of age at calving on lactation, reproduction, health, and income in first-parity Holsteins on commercial farms. J. Dairy Sci. 87:2730-2742.

Fourichon, C., F. Beaudeau, N. Bareille, and H. Seegers. 2001. Incidence of health disorders in dairy farming systems in western France. Livest. Prod. Sci. 68:157-170.

Gearhart, M. A., C. R. Curtis, H. N. Erb, R. D. Smith, C. J. Sniffen, L. E. Chase, and M. D. Cooper. 1990. Relationship of changes in condition score to cow health in Holsteins. J. Dairy Sci. 73:3132-3140.

Hansen, M., I. Misztal, M. S. Lund, J. Pedersen, and L. G. Christensen. 2004. Undesired phenotypic and genetic trend for stillbirth in Danish Holsteins. J. Dairy Sci. 87:1477-1486.

Heringstad, B., Y. M. Chang, M. Svendsen, and D. Gianola. 2007. Genetic analysis of calving difficulty and stillbirth in Norwegian Red cows. J. Dairy Sci. 90:3500-3507.

Heuwieser, W., U. Hartig, F. Offeney, and E. Grunert. 1987. Significance of glucocorticoids as a parameter of stress in cattle in the periparturient period. J. Vet. Med. 33:178-187.

Ingvartsen, K. L., R. J. Dewhurst, and N. C. Friggens. 2003. On the relationship between lactational performance and health: Is it yield or metabolic imbalance that cause production diseases in dairy cattle? A position paper. Livest. Prod. Sci. 83:277-308.

International Dairy Federation. 1987. Bovine Mastitis. Definition and Guidelines for Diagnosis. Bulletin No. 211. International Dairy Federation, Brussels, Belgium. 
Johanson, J. M., and P. J. Berger. 2003. Birth weight as a predictor of calving ease and perinatal mortality in Holstein cattle. J. Dairy Sci. 86:3745-3755.

Johnson, S. K., G. H. Deutscher, and A. Parkhurst. 1988. Relationships of pelvic structure, body measurements, pelvic area and calving difficulty. J. Anim. Sci. 66:1081-1088.

Manfredi, E., V. Ducrocq, and J. L. Foulley. 1991. Genetic analysis of dystocia in dairy cattle. J. Dairy Sci. 74:1715-1723.

Meijering, A. 1984. Dystocia and stillbirth in cattle - A review of causes, relations and implications. Livest. Prod. Sci. 11:143-177.

Meyer, C. L., P. J. Berger, K. J. Koehler, J. R. Thompson, and C. G. Sattler. 2001. Phenotypic trends in incidence of stillbirth for Holsteins in the United States. J. Dairy Sci. 84:515-523.

Nakao, T., and E. Grunert. 1990. Effects of dystocia on postpartum adrenocortical function in dairy cows. J. Dairy Sci. 73:2801-2806.

Peeler, E. J., M. J. Otte, and R. J. Esslemont. 1994. Inter-relationships of periparturient diseases in dairy cows. Vet. Rec. 134:129-132.

Rajala, P. J., and Y. T. Gröhn. 1998. Effects of dystocia, retained placenta, and metritis on milk yield in dairy cows. J. Dairy Sci. 81:3172-3181

Roche, J. R., P. G. Dillon, C. R. Stockdale, L. H. Baumgard, and M. J. VanBaale. 2004. Relationships among international body condition scoring systems. J. Dairy Sci. 87:3076-3079.

Roche, J. R., J. M. Lee, K. A. Macdonald, and D. P. Berry. 2007a. Relationships among body condition score, body weight and milk production variables in pasture-based dairy cows. J. Dairy Sci. 90:3802-3815.
Roche, J. R., J. M. Lee, K. M. Macdonald, C. R. Burke, and D. P. Berry. 2007b. Associations among body condition score, body weight and reproductive performance in seasonal-calving pasture-based dairy cattle. J. Dairy Sci. 90:376-391.

Rowlands, G. J., and S. Lucey. 1986. Changes in milk yield in dairy cows associated with metabolic and reproductive disease and lameness. Prev. Vet. Med. 4:205-221.

Ruegg, P. L., and R. L. Milton. 1995. Body condition scores of Holstein cows on Prince Edward Island, Canada: Relationships with yield, reproductive performance, and disease. J. Dairy Sci. 78:552-564.

Sainz, R. D., F. De la Torre, and J. W. Oltjen. 1995. Compensatory growth and carcass quality in growth-restricted and refed beef steers. J. Anim. Sci. 73:2971-2979.

SAS Institute. 2006. SAS/STAT Software. Release 9.1, SAS Institute, Inc., Cary, NC.

Steinbock, L., A. Näsholm, B. Berglund, K. Johansson, and J. Philipsson. 2003. Genetic effects of stillbirth and calving difficulty in Swedish Holsteins at first and second calving. J. Dairy Sci. 86:2228-2235.

Thompson, J. R., E. J. Pollak, and C. L. Pelissier. 1983. Interrelationships of parturition problems, production of subsequent lactation, reproduction, and age at first calving. J. Dairy Sci. 66:1119-1127.

Waltner, S. S., J. P. McNamara, and J. K. Hillers. 1993. Relationships of body condition score to production variables in high producing Holstein dairy cows. J. Dairy Sci. 76:3410-3419.

Wilmink, J. B. M. 1987. Adjustment of lactation yield for age at calving in relation to level of production. Livest. Prod. Sci. 16:321-334. 